\title{
MJN NURSE-LED INTERVENTION TO IMPROVE THE QUALITY OF LIFE AMONG ADULTS WITH TYPE 2 DIABETES UNDERGOING HEMODIALYSIS
}

\author{
Melba Sheila D'Souza ${ }^{1}$, Ramesh Venkatesaperumal' ${ }^{1}$, Jennifer Walden ${ }^{2}$, PramodKamble $^{3}$ \\ ${ }^{1}$ Abbotsford Regional Hospital and Cancer Centre, British Columbia, Canada \\ ${ }^{2}$ College of Nursing, Laxmi Memorial College of Nursing, India \\ ${ }^{3}$ Nephrology, Royal Hospital, Muscat, Sultanate of Oman \\ *Corresponding Author’s Email: melba123@rediffmail.com
}

\begin{abstract}
Aim: Chronic kidney disease is a progressive decline in renal function with a reduced glomerular filtration rate and proteinuria. The study evaluates the nurse-led intervention to improve the quality of life among adults with type 2 diabetes on hemodialysis. Methods: The study was a randomized controlled trial with a pre-test and post-test in a tertiary hospital. A random sample of 110 adults with type 2 diabetes (T2D) and end-stage renal disease (ESRD) in the intervention and 100 adults in the control group was selected for the study in 2017. General linear model and Repeated measures were done to determine the effects of the group. Results: A statistically significant main effect (between-groups), within-group (time) and interaction effects for intervention were detected in all the parameters across time from T2 to T3 in the intervention group. Conclusion: Nurse-led intervention had a positive effect on the kidney disease, physical and mental health among the adults with T2D and end-stage renal disease.
\end{abstract}

\section{Keywords: End Stage Renal Disease, Type-2 Diabetes, Hemodialysis, Nursing, Nurse-Led Intervention, Quality of Life}

\section{INTRODUCTION}

Long-term chronic kidney disease (CKD) leads to life-threatening metabolic disorder (Barasch \& Barasch, 2012) and end-stage renal disease (ESRD) (Ibrahim, 2015). CKD has the high prevalence in the general population due to aging, hypertension, glomerulonephritis (Shaw et al., 2013), diabetes mellitus (Gilg, Rao \& Fogarty, 2013), renal impairment and recurrent infection (Navaseelan, Judenimal \& Dioso, 2017). Hyperglycemia and HbAlc were high, dyslipidemia is associated with increased triglycerides, decreased LDL and HDL (Yanjmaal et al., 2018).Intake of energy drinks is a major determinant of developing kidney failure among the younger adults due to taurine that accumulates in the kidneys (Suliman et al., 2002), exceeding the recommended dosages of drinks, mixing energy drinks with alcohol or consuming after exercise may be harmful (Hanly, 2014). Adults with T2D and ESRD are at high risk for fatigue, weakness, and nutritional problems, poor social interaction and low quality of life (Horigan, Rocchiccioli \& Trimm, 2012). Adopting a healthy renal diet, learning to cope with illness, and compliance with dialysis may assist to improve their quality of life (QOL).

Quality of life refers to the adult's functioning, wellbeing, and health perception in physical, psychological, and social domains among adults with T2D and ESRD. Adults with type 2 diabetes (T2D) and ESRD are associated with high complications, poor QOL and lack of adherence to the renal replacement therapy (Fresenius Medical Care, 2013). Activity levels, functional ability, health status, and psychological status affect QOL among adults with ESRD (Fayers \& Machin, 2013). Hence adherence, compliance, exercise and engagement 
in activities pose challenges to adults with ESRD (Karolich \& Ford, 2010). Studies have shown that QOL is lower among adults with ESRD in comparison to the general population affected by dialysis efficiency, duration of dialysis, medical conditions, hemoglobin, anxiety, and depression.

Adults with T2D and h ESRD must adapt and cope with various stresses related to self-care management of their symptoms, illness, dialysis and change in activities of daily living, mobility, eating, medications and follow-up. These changes influence their physical, psychological and social health and well-being. In our study, the nurse-led intervention was developed for adults with T2D and ESRD taken from hospital to home so as to care to improve and sustain with positive effects for adults with T2D and ESRD. There is a great need for nurse-led interventions to enable the capabilities of adults with T2D and ESRD, to make informed decisions and confidence in their self-care management. The aim of this study is to examine the effectiveness of a nurseled intervention (NLI) designed to support adults with T2D to improve their quality of life.

\section{RESEARCH METHODOLOGY}

\section{Design}

The study was a randomized controlled trial with a pre-test and post-test. The renal dialysis unit of a local, regional hospital and community in India participated in the study. The study set up consisted of two groups: an intervention group using the nurse-led intervention and the control group receiving the usual care in the hospital and community.

\section{Population and sample}

Adults with T2D and ESRD accessing the renal dialysis unit of the regional hospital with 30 beds were recruited for the study. The inclusion criteria consisted of adults over 18 years, willing to volunteer and consent, able to understand the local language and English, ready to commit to the study needs and objectives, diagnosed with T2D and ESRD and undergoing hemodialysis and willing to adopt the nurse-led intervention. Patients with intermittent peritoneal dialysis, kidney transplants and life-threatening complications, neurological disorders like stroke, degenerative diseases and cognitive impairment were excluded from the study. The target population was adults with T2D and ESRD undergoing hemodialysis, who were admitted from $1^{\text {st }}$ January 2017 to $30^{\text {th }}$ July 2017 in the hospital.

\section{Sample size and power}

Based on Repeated measures analysis of variance, an estimated sample size of 210 (110 in the intervention group and 100 in the control group) was considered adequate to validate the effects of the nurse-led intervention (Figure 1). A total of 225 adults were allotted to the intervention and control group to reduce attrition and mortality. The design achieved $90 \%$ power with an alpha $<0.01$ ( $1 \%$ level of significance) and 0.80 effect size (Cohen, 1992).

\section{Measurements}

The primary outcome of the study is the quality of life measured by the Kidney Disease Quality of LifeShort form (KDQOL-SF) instrument. It is a self-report measure developed for individuals with kidney disease and on dialysis comprising of 79 items in the generic and kidney-targeted areas of QOL for adults with ESRD (Hays et al., 1997). It includes 43 kidney-disease targeted items and 36 items of SF that provide a generic score and an overall health rating item. It has 19 subscales and one free-standing question on overall health rating. The 8 subscales for the SF-36 are Physical functioning (10), Role-physical (4), Bodily pain (2), General health (5), Vitality (4), Social functioning (SF) (2), Role-emotional (RE) (3), and Mental health (5) and General QOL. The 11 subscales for kidney disease-specific focus on Symptoms/Problems (12), Effects of kidney disease on daily life (8), Burden of kidney disease (4), Work status (2), Cognitive function (3), Quality of social interaction (3), Sexual function (2), Sleep (4), Social support (2), Dialysis staff encouragement (2), adult satisfaction (1) (KDQOL-SF 1997). The reliability of the KDQOL-SF in this study was $r=0.90$.

Demographic variables were prepared consisting of age, gender, educational status, occupation, and family monthly income. Clinical variables include physical activity. The classification of ESRD (Kidney disease outcomes quality initiative) is based on the glomerular filtration rate $\left(\mathrm{mL} / \mathrm{min} / 1.73 \mathrm{~m}^{2}\right)$ as mild: $60-89$ $\mathrm{mL} / \mathrm{min} / 1.73 \mathrm{~m}^{2}$, moderate: $30-59 \mathrm{~mL} / \mathrm{min} / 1.73 \mathrm{~m}^{2}$ and severe: $15-29 \mathrm{~mL} / \mathrm{min} / 1.73 \mathrm{~m}^{2}$ by the KDQOL. Anemia was classified as $<80 \mathrm{~g} / \mathrm{L}$ as severe, $80-109 \mathrm{~g} / \mathrm{L}$ as moderate and 110-119 g/L (females) or 110-129 g/L (men) as mild (Benoist et al., 2008). Body mass index was categorized as normal: 18.5-24.9, pre-obesity: $25-$ 
29.9 and obesity class I: 30-34 (World Health Organization, 2004).

\section{Randomization}

Blocked randomization was used for blind selection of adults to the allocated treatment across the intervention and control groups. The selected adults in the intervention group were given nurse-led intervention at two-time intervals within a period of 6 weeks after the baseline data (pretest T1) was gathered and the consecutive 6 weeks after the posttest T2. The adults in the nurse-led intervention were asked to maintain the confidentiality of the intervention for the study purpose.

A triple blinding technique was used to maintain the confidentiality of the data outcome measures. Both the intervention and the control group were treated equally regarding the selection, randomization, administration of the data collection instruments and ethical protocol, except for the nurse-led intervention. Randomization took place daily in the dialysis center until the total sample size was reached in the intervention group and the control group after the baseline data (T1).

\section{Quality and Rigor of the Intervention}

A nurse-led intervention (NLI) protocol was developed by the researchers and validated by the renal specialist nurses, physicians, psychologists and counselors. Adults with T2D and ESRD in the intervention group received a comprehensive NLI for 4 hours in first 6 weeks (total of 24 hours) after the pretest $\mathrm{T} 1$ and a repeat of the NLI of 4 hours duration in the consecutive 6 weeks nurse-led intervention. A total of 48 hours of NLI was delivered using a structured video, interactive discussion, concept mapping, problemsolving and a motivation interview. The nurse led intervention was initiated face to face with the intervention group after the pretest T1 for 6 weeks and after the posttest $\mathrm{T} 2$ for the consecutive 6 weeks (a total of 12 weeks).

The nurse-led intervention included a discussion about self-care management, psycho-educational and counseling on lifestyle, activities of daily living, identifying symptoms, effects on kidney disease and complications, changes in adjusting to working, diet, exercise, pain, medication adherence. The NLI included discussion about the energy conservation, gradual improvement in activities, coping skills, interpersonal, family and social interactions, changes in sexual life, sleep management, psychosocial and emotional support, quitting smoking and alcohol to maintain a near healthy lifestyle. NLI was carried out by two trained renal nurse specialist in the local vernacular Kannada and Konkani language before the dialysis for adults with T2D and ESRD in the hospital.

The motivational interview checklist was used to understand the adults' perspectives, follow up on the NLI and confidence and autonomy of managing selfcare using the NLI was done. A realistic nurse-led intervention was planned to incorporate adult's preferences, exercise, medication, fluid and diet adherence behaviors, technical procedures for dialysis and avoidance of infection. Family participation was encouraged to support and perform roles as caregivers in the recovery process. The NLI was videotaped with informed consent for quality, consistency, validity, rigor and documentation.

Adults in the control group received routine hospital care, regular discharge care, standard information, and a printed book. The control group received the usual hospital care, and they did not have any access or knowledge of the nurse-led interventions in the study. They were provided with the nurse-led intervention only on completion of the study to maintain the ethics.

\section{Data collection}

The data were collected from $1^{\text {st }}$ January 2017 to 30 July 2017 at three-time intervals (T1 as a baseline on day 0, $\mathrm{T} 2$ at the end of 6 weeks and T3 at the end of 12 weeks) using a structured self-report questionnaire and face-toface interview. Outcome data collected at T1 provided the baseline for comparison, $\mathrm{T} 2$ to determine the immediate intervention effects and $\mathrm{T} 3$ data to detect sustaining results of the nurse-led intervention. The purpose of the study, the right to participate or withdraw from the study was explained using written and verbal documents. Informed written and verbal consent was obtained from the selected adults.

\section{Ethical considerations}

The study was approved by the Hospital and Medical Ethics Board of the study. The permission to research dialysis unit was obtained from concerned authorities. The eligible adults were identified from the 
hospital medical records after securing agreement. Human ethical principles were adhered to the study.

\section{Analysis}

Comparisons were made between the two groups of adults with T2D and ESRD. Descriptive statistics were compared for demographic variables. SPSS version 21 was used to perform statistical analysis. Paired and independent $t$-test was applied to determine the effectiveness of the nurse-led intervention. Test of homogeneity indicated no significant difference between the groups in the demographic and clinical variables. A general linear model was used to determine the between-group (intervention), withingroup (times) and interactions (time-group) effect to identify statistically significant differences in patterns between groups over time. When a statistically significant $(p<0.05)$ difference was found, Repeated measures were performed to determine which group contributed to the effects.

\section{RESULTS}

A total sample of 250 adults with T2D and ESRD who met the selection criteria was randomly selected for the study. Among these, a total of 225 adults with T2D and ESRD were recruited into the study and they were randomly assigned to the intervention group $(n=113)$ and the control group $(n=112) .110$ adults in the intervention group and 100 adults in the control group completed the study and were analyzed (Figure 1).

\section{Enrollment}

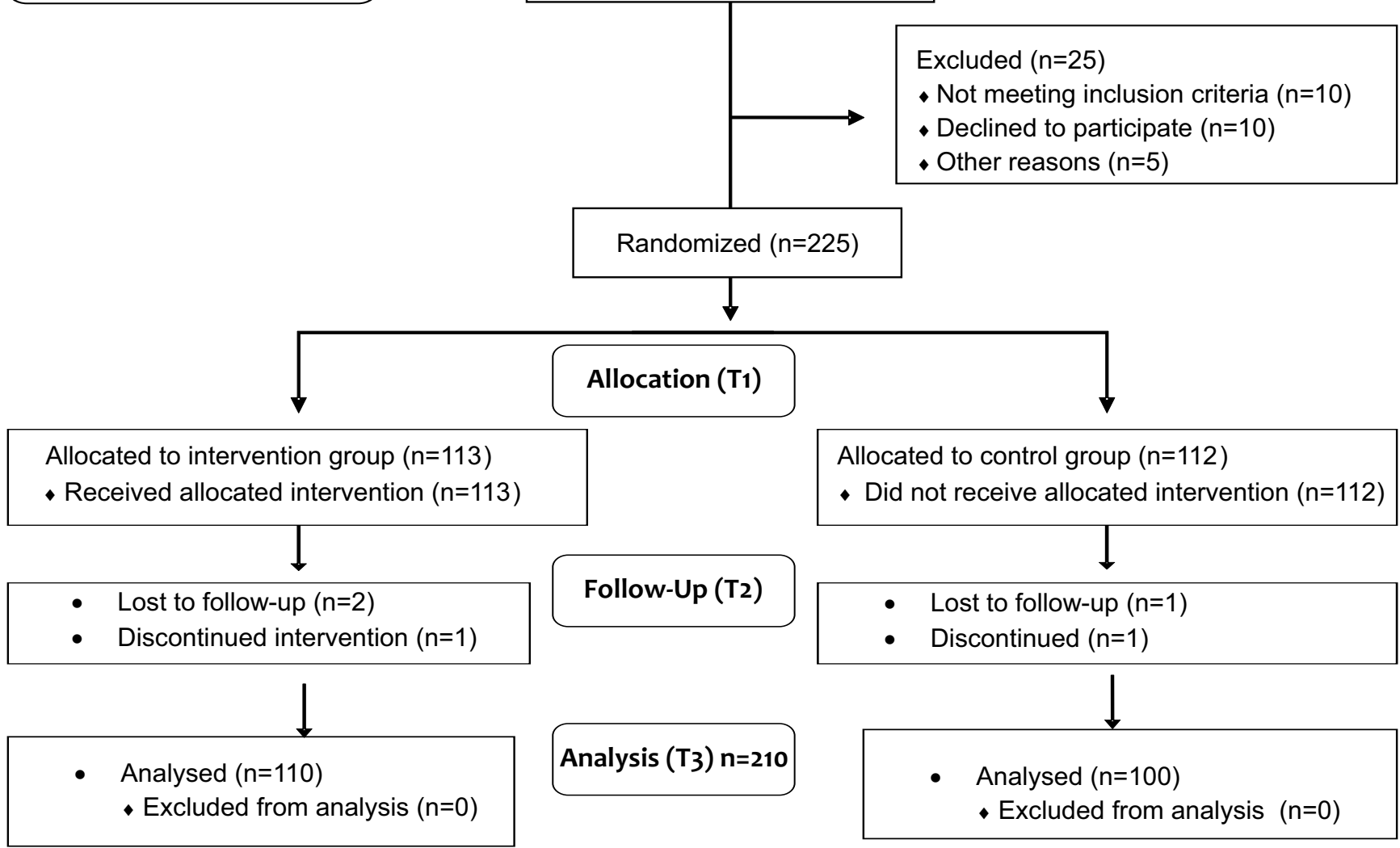

Figure 1: CONSORT flow diagram for renal study

Chi-square comparison and $t$-test showed no significant differences among the demographic and clinical characteristics between the intervention and control group (Table 1 and Table 2 respectively). This association confirms the randomization and homogeneous characteristics among the adults with T2D and ESRD in the intervention and control groups. 
Table 1: Demographic Characteristics among Adults with End Stage Renal Disease

\begin{tabular}{|c|c|c|c|}
\hline Variable/ Categories & $\begin{array}{l}\text { Intervention } \\
\text { Group } \mathrm{F}(\%), \\
\mathrm{N}=110\end{array}$ & $\begin{array}{l}\text { Control } \\
\text { Group N } \\
\mathrm{F}((\%), \\
\mathrm{N}=100\end{array}$ & $\begin{array}{l}\chi^{2} / t \text {-test } \\
P \text { value }\end{array}$ \\
\hline Age ( in years) & & & $0.23^{\#}$ \\
\hline 20 to 34 years & $14(12.7)$ & $9(9)$ & \\
\hline 35 to 49 years & $37(33.6)$ & 39 (39) & \\
\hline 50 to 64 years & $48(43.6)$ & $41(41)$ & \\
\hline Above 65 years & $11(10.1)$ & $11(11)$ & \\
\hline Gender & & & $0.46^{*}$ \\
\hline Male & $62(56.4)$ & $61(61)$ & \\
\hline Female & $48(43.6)$ & 39 (39) & \\
\hline Educational status & & & $0.62^{*}$ \\
\hline Primary school & $34(30.9)$ & $35(35)$ & \\
\hline SSLC & $41(37.3)$ & $33(33)$ & \\
\hline Bachelor & $25(22.7)$ & $23(23)$ & \\
\hline Master & $10(9.1)$ & $9(9)$ & \\
\hline Occupation & & & $0.19 *$ \\
\hline Unskilled & $38(34.6)$ & $34(34)$ & \\
\hline Skilled & $58(52.7)$ & $53(53)$ & \\
\hline Professional & $14(12.7)$ & $13(13)$ & \\
\hline Income in USD (INR) & & & $0.69 *$ \\
\hline$<156.9(10,000)$ & $37(33.6)$ & $41(41)$ & \\
\hline $157-624.9(10,001-40,000)$ & $48(43.6)$ & $45(45)$ & \\
\hline $625(>40,001)$ & $25(22.8)$ & $14(14)$ & \\
\hline
\end{tabular}

*Pearson chi-square test $<0.05$ using $95 \%$ confidence interval; \#Independent sample t-test

The significant variables were Symptoms, Effects of kidney disease, Burden of kidney disease, Work status, Cognitive function, Quality of social interaction, Sexual function across $\mathrm{T} 2$ and $\mathrm{T} 3$ in the intervention group (Table 3). Repeated measures were used to determine the attribution of time effects from the two groups separately for the groups at the three-time intervals. Intervention group adults showed marked improvements after the
Table 2: Clinical Characteristics among Adults with End Stage Renal Disease

\begin{tabular}{|c|c|c|}
\hline Variable/ Categories & $\begin{array}{l}\text { Intervention } \\
\text { Group } \\
\mathrm{N}=110(\%) \\
\mathrm{N} \text { (Percentage) }\end{array}$ & $\begin{array}{l}\text { Control Group } \\
\mathrm{N}=100(\%) \\
\mathrm{N} \text { (Percentage) }\end{array}$ \\
\hline Physical activity & & $0.47^{*}$ \\
\hline Sedentary & $24(21.8)$ & $30(30)$ \\
\hline Moderate & $51(46.4)$ & $40(40)$ \\
\hline Heavy & 35 (31.8) & $30(30)$ \\
\hline Anemia(g/L) & & $0.57 \#$ \\
\hline$<80 \mathrm{~g} / \mathrm{L}$ & $14(12.7)$ & $17(17)$ \\
\hline $80-109 \mathrm{~g} / \mathrm{L}$ & $52(47.3)$ & $43(43)$ \\
\hline $\begin{array}{l}110-119 \mathrm{~g} / \mathrm{L} \text { or } 110-129 \mathrm{~g} / \mathrm{L} \\
\text { (men) }\end{array}$ & $44(40)$ & $40(40)$ \\
\hline $\begin{array}{l}\text { Glomerular filtration rate } \\
\left(\mathrm{mL} / \mathrm{min} / 1.73 \mathrm{~m}^{2}\right)\end{array}$ & & $0.59 \#$ \\
\hline Mild: $60-89 \mathrm{~mL} / \mathrm{min} / 1.73 \mathrm{~m}^{2}$ & $53(48.2)$ & $45(45)$ \\
\hline $\begin{array}{l}\text { Moderate: } 30-59 \\
\mathrm{~mL} / \mathrm{min} / 1.73 \mathrm{~m}^{2}\end{array}$ & $37(33.6)$ & $36(36)$ \\
\hline Severe: $15-29 \mathrm{~mL} / \mathrm{min} / 1.73 \mathrm{~m}^{2}$ & $20(18.2)$ & 19 (19) \\
\hline Body mass index & & $0.68 \#$ \\
\hline Normal: 18.5-24.9 & $41(37.3)$ & $33(33)$ \\
\hline Pre-obesity: 25-29.9 & $44(40)$ & $46(46)$ \\
\hline Obesity class I: 30-34.9 & $25(22.7)$ & $21(21)$ \\
\hline
\end{tabular}

*Pearson chi-square test, $P<0.05$ using $95 \%$ confidence interval, Independent sample t-test

intervention, with the effect of improvement in the following six weeks. There was a marked decrease in the mean scores of the various KDQOL dimensions in T2 from $\mathrm{T} 1$ and later the mean scores remained slightly higher or similar after 12 weeks among the control group. The control group did not display any improvement during the first 12 weeks or the in the consecutive weeks and had a lesser degree of change. 


\section{Effect of intervention over time and outcome measures}

Table 3: Kidney disease Quality of Life in intervention group $(N=110)$ and control group $(N=100)$ : Mean score and change over time

\begin{tabular}{|c|c|c|c|c|c|c|c|c|c|}
\hline Time & \multicolumn{3}{|c|}{ Pre-test (T1) } & \multicolumn{3}{|c|}{ Post-test I (T2) } & \multicolumn{3}{|c|}{ Post-test II (T3) } \\
\hline $\begin{array}{l}\text { Group } \\
\text { Outcome measures }\end{array}$ & $\begin{array}{l}\text { Intervention } \\
\text { Group }\end{array}$ & $\begin{array}{l}\text { Control } \\
\text { group }\end{array}$ & $\begin{array}{l}\text { Independent } \\
t \text { test }\end{array}$ & $\begin{array}{l}\text { Intervention } \\
\text { Group }\end{array}$ & $\begin{array}{l}\text { Control } \\
\text { group }\end{array}$ & $\begin{array}{l}\text { Independent } \\
t \text { test }\end{array}$ & $\begin{array}{l}\text { Intervention } \\
\text { Group }\end{array}$ & $\begin{array}{l}\text { Control } \\
\text { group }\end{array}$ & $\begin{array}{l}\text { Independent } \\
t \text { test }\end{array}$ \\
\hline KDQOL & Mean (SD) & $\operatorname{Mean}(S D)$ & $P$ value & Mean (SD) & Mean (SD) & $P$ value & Mean (SD) & Mean (SD) & $P$ value \\
\hline Symptom/ problem list & $62(12.5)$ & $59(7.9)$ & 0.23 & $83(8.9)$ & $37(6.6)$ & $0.000 * * *$ & $92(6.4)$ & $54(13.5)$ & $0.000 * * *$ \\
\hline Effect of kidney disease & $57(14.2)$ & $55(8.9)$ & 0.46 & $75(9.3)$ & $47(13.2)$ & $0.000 * * *$ & $89(7.4)$ & $49(14.2)$ & $0.000 * * *$ \\
\hline Burden of kidne ydisease & $44(13.1)$ & $40(12.7)$ & 0.38 & $70(14.1)$ & $18(9.3)$ & $0.000 * * *$ & $64(9.3)$ & $36(16.1)$ & $0.000 * * *$ \\
\hline Work status & $35(15.7)$ & $45(13.6)$ & 0.04 & $40(13.9)$ & $25(15.7)$ & $0.000 * * *$ & $52(5.9)$ & $27(15.7)$ & $0.000 * * *$ \\
\hline Cognitive function & $67(14.4)$ & $66(12.3)$ & 0.19 & $85(11.8)$ & $40(11.2)$ & $0.000 * * *$ & $83(8.2)$ & $59(17.4)$ & $0.000 * * *$ \\
\hline $\begin{array}{l}\text { Quality of social } \\
\text { interaction }\end{array}$ & $69(11)$ & $64(14.3)$ & 0.06 & $74(10.3)$ & $27(10.6)$ & $0.000 * * *$ & $82(7.3)$ & $61(18.0)$ & $0.000 * * *$ \\
\hline Sexual function & $53(17)$ & $63(12.4)$ & 0.11 & $74(8.5)$ & $43(14.0)$ & $0.000 * * *$ & $78(7.7)$ & $45(17.0)$ & $0.000 * * *$ \\
\hline Sleep & $52(12.8)$ & $50(11.1)$ & 0.19 & $65(10.1)$ & $42(14.8)$ & $0.000 * * *$ & $72(9)$ & $44(13.8)$ & $0.000 * * *$ \\
\hline Social support & $73(14.7)$ & $66(13.8)$ & 0.20 & $83(12.2)$ & $63(14.7)$ & $0.000 * * *$ & $99(5.1)$ & $65(14.7)$ & $0.000 * * *$ \\
\hline $\begin{array}{l}\text { Dialysis staff } \\
\text { encouragement }\end{array}$ & $70(14.6)$ & $70(15.3)$ & 0.36 & $86(14.6)$ & $60(14.6)$ & $0.000 * * *$ & $93(4.2)$ & $62(14.6)$ & $0.000 * * *$ \\
\hline Overall health & $59(17)$ & $57(14.2)$ & 0.47 & $70(11.6)$ & $49(15.0)$ & $0.000 * * *$ & $75(4.6)$ & $51(16.0)$ & $0.000 * * *$ \\
\hline Patient satisfaction & $82(13)$ & $79(13.2)$ & 0.54 & $94(10.8)$ & $72(14.0)$ & $0.000 * * *$ & $99(3.8)$ & $74(13.0)$ & $0.000 * * *$ \\
\hline
\end{tabular}

Table 4: General Linear Model among adults with the end-stage renal disease between the intervention and control group KDQOL

\begin{tabular}{|c|c|c|c|c|c|c|}
\hline \multirow{2}{*}{$\begin{array}{l}\text { Outcome measures } \\
\text { KDQOL }\end{array}$} & \multicolumn{2}{|c|}{ Between-group } & \multicolumn{2}{|c|}{ Within-group } & \multicolumn{2}{|c|}{ Interaction effect } \\
\hline & $\mathrm{F}$ & $P$ value & $\mathrm{F}$ & $P$ value & $\mathrm{F}$ & $P$ value \\
\hline Symptom/ problem list & 0.53 & 0.46 & 4.38 & $0.01 *$ & 0.36 & $0.03 *$ \\
\hline Effect of kidney disease & 0.11 & 0.54 & 3.48 & $0.03^{*}$ & 0.67 & $0.05^{*}$ \\
\hline The burden of kidney disease & 0.10 & 0.43 & 1.03 & $0.05^{*}$ & 1.02 & $0.04 *$ \\
\hline Work status & 0.53 & 0.46 & 0.82 & 0.45 & 0.26 & 0.78 \\
\hline Cognitive function & 2.14 & 0.32 & 0.27 & 0.76 & 0.27 & 0.58 \\
\hline Quality of social interaction & 0.91 & 0.56 & 1.29 & $0.05^{*}$ & 0.46 & 0.73 \\
\hline Sexual function & 0.56 & 0.48 & 2.73 & 0.23 & 1.82 & 0.45 \\
\hline Sleep & 0.12 & 0.54 & 3.28 & $0.04 *$ & 1.67 & 0.74 \\
\hline Social support & 0.91 & 0.76 & 0.37 & 0.47 & 0.83 & 0.71 \\
\hline Dialysis staff encouragement & 2.18 & 0.28 & 0.27 & $0.04 *$ & 9.45 & $0.05^{*}$ \\
\hline Overall health & 0.18 & 0.45 & 0.38 & $0.05^{*}$ & 0.75 & $0.05^{*}$ \\
\hline Patient satisfaction & 0.31 & 0.32 & 0.38 & $0.03 *$ & 0.54 & $0.04 *$ \\
\hline
\end{tabular}

***Statistically significant at $P<0.001$ using $95 \%$ confidence interval, Kidney Disease Quality of Life (KDQOL) 
A statistically significant main effect (between-groups), within-group (time) and interaction effects for intervention were observed in all the parameters across time from T2 to T3 in the intervention group (Table 4).

Table 5: Independent t-test among the Intervention and Control group General QOL among adults with ESRD

\begin{tabular}{|c|c|c|c|c|c|c|c|c|c|}
\hline \multirow{2}{*}{$\begin{array}{l}\text { Time } \\
\text { Group }\end{array}$} & \multicolumn{3}{|c|}{ Pre Test (T1) } & \multicolumn{3}{|c|}{ Post Test I (T2) } & \multicolumn{3}{|c|}{ Post Test II (T3) } \\
\hline & $\begin{array}{l}\text { Intervention } \\
\text { Group }\end{array}$ & $\begin{array}{l}\text { Control } \\
\text { Group }\end{array}$ & $\begin{array}{l}\text { Independent } \\
t \text {-test }\end{array}$ & $\begin{array}{l}\text { Intervention } \\
\text { Group }\end{array}$ & $\begin{array}{l}\text { Control } \\
\text { Group }\end{array}$ & $\begin{array}{l}\text { Independent } \\
t \text {-test }\end{array}$ & $\begin{array}{l}\text { Intervention } \\
\text { Group }\end{array}$ & $\begin{array}{l}\text { Control } \\
\text { Group }\end{array}$ & $\begin{array}{l}\text { Independent } \\
t \text {-test }\end{array}$ \\
\hline General QOL & Mean (SD) & Mean (SD) & $P$ value & Mean (SD) & & $P$ value & Mean (SD) & Mean(SD) & $P$ value \\
\hline $\begin{array}{l}\text { Physical } \\
\text { functioning }\end{array}$ & $50(12.36)$ & $45(15.56)$ & 0.298 & $72(14.74)$ & $32(15.16)$ & $0.000 * * *$ & $92(10.22)$ & $42(12.23)$ & $0.000 * * *$ \\
\hline Role physical & $45(14.07)$ & $40(14.63)$ & 0.503 & $82(14.64)$ & $27(19.21)$ & $0.000 * * *$ & $93(13.41)$ & $37(14.07)$ & $0.000 * * *$ \\
\hline Pain & $65(15.31)$ & $60(14.27)$ & 0.258 & $83(13.04)$ & $39(14.06)$ & $0.000 * * *$ & $90(12.2)$ & $57(15.31)$ & $0.000 * * *$ \\
\hline General Health & $53(14.29)$ & $51(13.81)$ & 0.224 & $60(12.88)$ & $30(11.83)$ & $0.000 * * *$ & $67(9.63)$ & $43(16.05)$ & $0.000^{* * *}$ \\
\hline $\begin{array}{l}\text { Emotional well } \\
\text { being }\end{array}$ & 64(13.7) & $60(15.23)$ & 0.107 & $68(13.51)$ & $38(13.14)$ & $0.000 * * *$ & $72(8.03)$ & $56(13.7)$ & $0.000^{* * *}$ \\
\hline Role emotional & $57(17.23)$ & 49(19.82) & 0.119 & $88(16.07)$ & $32(10.49)$ & $0.000 * * *$ & $99(7.83)$ & 49(17.23) & $0.000 * * *$ \\
\hline Social function & $64(16.66)$ & $60(16.4)$ & 0.237 & $81(15.7)$ & $33(12.45)$ & $0.000^{* * *}$ & $85(10.18)$ & $56(16.66)$ & $0.000 * * *$ \\
\hline Energy/Fatigue & $54(13.39)$ & $55(15.24)$ & 0.62 & $61(11.92)$ & $49(10.58)$ & $0.000 * * *$ & $67(11.49)$ & $46(14.39)$ & $0.000 * * *$ \\
\hline
\end{tabular}

The significant variables were Physical functioning, physical role, Pain, General Health, Emotional wellbeing, Role-emotional, Social interaction and Energy across T2 and T3 in the intervention group (Table 5). Repeated measures were used to determine the attribution of time effects from the two groups separately for the groups at the three-time intervals from $\mathrm{T} 1$ to $\mathrm{T} 2$ and $\mathrm{T} 3$. Intervention group adults showed marked improvements after the intervention, with the effect of improvement in the following six weeks, and the consecutive 12 weeks. Mean scores of the various QOL dimensions decreased during the first six weeks and the consecutive 12 weeks among the control group. The control group did not display any improvement during the first 12 weeks or the in the successive weeks and had a lesser degree of change in $\mathrm{T} 2$ and $\mathrm{T} 3$.

Table 6: General Linear Model for the Intervention and Control group General QOL across changes in time

\begin{tabular}{|l|c|c|c|c|c|c|}
\hline Outcome measures & \multicolumn{2}{|c|}{$\begin{array}{c}\text { Between } \\
\text { group }\end{array}$} & \multicolumn{2}{c|}{ Within-group } & \multicolumn{2}{c|}{$\begin{array}{c}\text { Interaction } \\
\text { effect }\end{array}$} \\
\hline General QOL & $\mathrm{F}$ & $\begin{array}{c}P \\
\text { value }\end{array}$ & & $\begin{array}{c}P \\
\text { value }\end{array}$ & $\begin{array}{c}P \\
\text { value }\end{array}$ \\
\hline Physical functioning & 0.00 & 0.30 & 0.83 & $0.04^{*}$ & 2.36 & $0.04^{*}$ \\
\hline Role physical & 0.27 & 0.35 & 4.57 & $0.0 *^{*}$ & 1.27 & $0.02^{*}$ \\
\hline Pain & 0.82 & 0.47 & 4.27 & $0.05^{*}$ & 1.28 & $0.03^{*}$ \\
\hline General Health & 0.73 & 0.38 & 0.56 & 0.73 & 1.28 & 0.24 \\
\hline Emotional well being & 0.29 & 0.54 & 4.38 & $0.01^{*}$ & 0.17 & 0.28 \\
\hline Role emotional & 0.82 & 0.38 & 1.04 & $0.00^{*}$ & 4.38 & $0.02^{*}$ \\
\hline Social function & 0.34 & 0.43 & 4.78 & $0.02^{*}$ & 3.48 & $0.01^{*}$ \\
\hline Energy/Fatigue & 1.00 & 0.28 & 1.28 & 0.32 & 0.35 & $0.04^{*}$ \\
\hline
\end{tabular}

${ }^{*} P<0.05 ; 95 \%$ confidence interval
A statistically significant main effect (betweengroups), within-group (time) and interaction effects for intervention were observed in all the parameters across time from T2 to T3 in the intervention group (Table 6). The significant differences in the intervention group contributed to within-group (Physical functioning, physical Pain, Emotional well-being, Role-emotional and Social function) and interaction effects (Physical functioning, Role physical, Pain, Role-emotional, Social function and Energy). The interaction effect for Physical functioning $(p=0.04)$, Role-physical $(p=0.02)$, Pain $(p=0.03)$ and Energy $(p=0.04)$ showed a trend towards statistical significance indicating that rates of improvement between the two groups across time were highly significant. This implies that the effect size of the nurse-led intervention was clinically significant withingroup and interaction effects were observed for QOL scores from $\mathrm{T} 1$ to $\mathrm{T} 3$ among adults with T2D and ESRD in the intervention group.

Table 7: Association between demographic and clinical characteristics using Chi square

\begin{tabular}{|l|c|c|}
\hline Variables & Intervention group & Control group \\
\hline Age & $0.001^{*}$ & $0.001^{*}$ \\
\hline Gender & $0.001^{*}$ & $0.001^{*}$ \\
\hline Educational status & $0.001^{*}$ & 0.622 \\
\hline Occupation & 0.579 & 0.501 \\
\hline Income & 0.503 & 0.401 \\
\hline Frequency of dialysis per week & 0.358 & 0.778 \\
\hline Physical activity & 0.408 & 0.812 \\
\hline Hemoglobin & $0.002^{*}$ & $0.002^{*}$ \\
\hline Glomerular filtration rate level & $0.033^{*}$ & $0.023^{*}$ \\
\hline Body mass index & $0.011^{*}$ & 0.111 \\
\hline *Significantatp<0.05 & &
\end{tabular}

*Significant at $p<0.05$ 
Higher age group, male gender, higher hemoglobin and lower glomerular filtration rate were significantly associated with KDQOL mean scores among adults in the intervention and control groups (Table 7).

\section{DISCUSSION}

The study confirmed that QOL among adults with T2D and ESRD in the intervention group was higher than the control group, with $75 \%$ of the KDQOL taking into consideration such symptoms like effect of kidney disease, the burden of kidney disease, staff encouragement, overall health and adult satisfaction. Nurse-led interventions were associated with improved symptoms like sleep, staff encouragement, pain, general health perception, energy/fatigue, overall health and mental component summary after six weeks of the intervention. These interventions focused on personal, physical and psychosocial dimensions of the QOL. There was continuity of nursing from the hospital, to the community and home care for an adult with ESRD in the intervention group. Self-management support and telephone-guided access (Blakeman et al., 2014) showed higher mean HRQOL in the intervention group $(1.85,95 \% \mathrm{CI}=1.25,2.72)$. Adults exposed to Psychoeducational interviewing had higher levels of adherence (Garc1'a-Llana et al., 2014; Kutner, 2012). This shows that adults with ESRD have reported better social and role functioning and emotional well-being in the intervention group.

Within the general dimensions of KDQOL-SF, the intervention group experienced higher QOL and reported a better Physical functioning, Role physical, less Pain, improved Role emotional, fewer problems with Social function, and more Energy as compared to control group. Early detection and intervention for sleep disorder among adults helped to reduce the sleep-related illness so as to promote better QOL. Pain reduction and adherence to medication and medical treatment among adults with T2D and ESRD are due to effective nurse-led interventions. Pain reduction among these adults' causes less interference with normal work activities resonates with the improvements in emotional well-being and social functioning. Low mean scores of anxiety and depression occurred in the intervention group exposed to the Fordyce Happiness program (Mehrabi, Ghazavi \& Hahgholian, 2017). Dialysis and the multidisciplinary team helped adults to improve health outcomes (Strand \& Parker 2012; Chen et al., 2016). Informed adults have reported fewer symptomsas well as more confidence in their ability to manage the symptoms they do have.

From the study, it was evident that exercise modified symptoms like reducing sleep disturbances, depression and pain and improved QOL among adults with T2D and ESRD. Pain reduction leads to less limitation in daily activities and better social functioning and emotional well-being. In this study, Nurse-led intervention (NLI) included adult education, counseling for various sleep disturbance and follow-up to monitor effectiveness. Diet and medication adherence lead to improved hemoglobin levels with improved QOL. Higher health status leads to higher well-being and increases in QOL. NLI is adultcentered goals and needs to identify problems and find mutually acceptable solutions to improve the QOL. Exercise is useful to improve the physical function and health self-perception and in alleviating symptoms such as fatigue, sleep disturbances, anxiety, depression and pain (Tao, Chow \& Wong, 2015). Exercises enhanced physical, mental health and general QOL among adults with ESRD. Sports therapy (Riyahi et al., 2012), Tai Chi exercise (Shahgholian, Eshghinezha \& Mortazavi, 2014) and Physical exercise (Bayoumi \& Al Wakeel, 2015) improved physical dimensions among adults on hemodialysis. Encouragement from family members and hospital staff members helped to increase autonomy and participation in their self-care management.

In our study better QOL mean scores were observed among middle age, men with higher income and undergoing dialysis more than once/week, which was significantly associated with higher QOL after an intervention. Adults with T2D and ESRD with good hemoglobin level elevated glomerular filtration rate, and low BMI were associated with higher QOL after intervention at six weeks and 12 weeks in the intervention group. Men who are independent, self-controlled, having good family support and good biochemical control have better QOL in the intervention group. Cognitive function and quality of social interaction and QOL were associated with older age among adults on hemodialysis (Brown et al., 2010). Education influenced the physical and social domains of QOL as they are aware of the quality of service and individual rights (Bayoumi \& El-Fouly, 2010).

In this study, physical composite scores (PCS) were correlated with age, hemoglobin and comorbidity and mean PCS was lower in adults with healthy weight or 
moderately high BMI. QOL of the intervention group was higher than the control group in $50 \%$ of the dimensions in KDQOL and reported better emotional state, less bodily pain, improved social functioning. QOL increased by $20 \%$ with regards to coping among adults with hemodialysis (Barahimi et al., 2015). Here, the intervention group had higher general QOL and KDQOL compared to control group, except for energy fatigue, emotional well-being, social function and energy fatigue, work status, quality of social interaction, and social support. Physical and mental composites of general QOL were higher in the intervention group compared to the control group. In this study, a lower reduction in KDQOL was observed among elderly adults with T2D and ESRD compared to the younger adults. Change in perceptions of adult's functional ability predicted their QOL which influenced of subdomains of QOL differently.

The nurse-led intervention was associated with improved QOL regarding symptoms, sleep, pain, staff encouragement, energy/fatigue, mental well being and physical component with self-care management and adjustments. The intervention group demonstrated higher QOL with respect to psychosocial concerns, feeling more energetic and a better lifestyle to delay disease progression. The NLI included motivational interviewing before and after discharge by responding to adult's experiences of illness and integrating the demands of therapeutic regimens into their lifestyles. The results of this study are useful for evaluating the effectiveness of NLI based on mutually agreed goals to improve QOL among adults with ESRD and hemodialysis. It has been proven that nurse-led intervention is beneficial and it helps to improve the QOL among adults with T2D and ESRD.

The limitation of this study was a small sample size, data analysis for the integrated nurse-led interventions along with short time duration and intervals of the responses and interventions (total of 6 hours before the 6 and 12 weeks) and effect of the nurse-led interventions on outcomes over time (T2 and T3).

\section{CONCLUSION}

A nurse-led intervention was shown to be a positive predictor of physical and mental health for people with T2D and ESRD as they have reported fewer symptoms and an increase in the confidence level to manage the symptoms. NLI was associated with improvement in the self-efficacy, self-care behaviors by encouraging adult's autonomy and increasing rapport between the nurses and client to engender behavioral change and improved QOL. NLI have an impact on adults QOL changes with education and exercise, encouragement and engagement and enables them to accept responsibility for their health. Adults with T2D and ESRD can take more accountability for things they can control like exercise, active involvement in life and a meal plan to positively affect their participation in a productive life. Adults with T2D and ESRD on hemodialysis are encouraged and reinforced to learn about their self-care for improved quality of life. Encouragement and counseling, especially from inter-professional dialysis team, can increase autonomy, control and participation. Interactive adult learning goals, choices, medications, and the diet can help adults with T2D and ESRD to maintain a sense of control, a factor linked to improved QOL.

\section{REFERENCES}

Barahimi, H., Abolhassani, F., Rajaee, F. \& Akbari Sari, A. (2015). A multilevel model for services provided to patients with chronic kidney disease. Iranian Journal of Kidney Diseases, 9(3), pp 186-192.

Barasch, J. \& Barasch, N. (2013). High molecular weight NGAL as a biomarker for chronic kidney disease. U.S. Patent No. 8,592,170. Washington, DC. Retrieved from: https://patents.google.com/patent/US8592170B2/en

Bayoumi, M. \& El-Fouly, Y. (2010). Effects of teaching programme on quality of life for patients with the end-stage renal disease. Journal of Renal Care, 36(2), pp 96-101.

Bayoumi, M.M. \& Al Wakeel, J.S. (2015). Impacts of Exercise programs on Hemodialysis patients' Quality of Life and Physical Fitness. Quality in Primary Care, 23(4), pp 192-200.

Benoist, B. D., McLean, E., Egll, I., \& Cogswell, M. (2008). Worldwide prevalence of anemia 1993-2005: WHO 
global database on anemia. Worldwide prevalence of anemia 1993-2005: WHO global database on anemia. Retrieved from:http://apps.who.int/iris/bitstream/handle/10665/43894/9789241596657_eng.pdf; jsessionid=602CAB7DABECE243CD92F9CC77169D0C? sequence $=1$.

Blakeman, T., Blickem C., Kennedy A., Reeves D., Bower P., Gaffney, H., Gardner, C., Lee, V., Jariwala, P., Dawson, S., Mossabir, R., Brooks, H., Richardson, G., Spackman, E., Vassilev, I., Chew-Graham, C. \& Rogers, A. (2014). Effect of Information and Telephone-Guided Access to Community Support for People with Chronic Kidney Disease: Randomised Controlled Trial. PLoSONE, 9(10), pp e109135.

Brown, E.A., Johansson, L., Farrington, K., Gallagher, H., Sensky, T., Gordon, F., Da Silva-Gane, M., Beckett, N. \& Hickson, M. (2010). Broadening Options for Long-term Dialysis in the Elderly (BOLD): differences in quality of life on peritoneal dialysis compared to hemodialysis for older patients. Nephrology Dialysis Transplantation, 25(11), pp 3755-3763.

Chen, C.C., Chen, Y., Liu, X., Wen, Y., Ma, D.Y., Huang, Y.Y., Pu, L., Diao, Y.S. \& Yang, K. (2016). The Efficacy of a Nurse-Led Disease Management Program in Improving the Quality of Life for patients with Chronic Kidney Disease:A Meta-Analysis. PLoSONE, 11(5), pages 16.

Cohen, J. (1992). A power primer. Psychological Bulletin, 112(1), pp 155-159.

Fayers, P.M. \& Machin, D. (2015). Quality of life: the assessment, analysis, and interpretation of patient-reported outcomes. John Wiley \& Sons, USA.

Fresenius Medical Care. (2013). Annual Report 2013. Retrieved from: http://www.fmc- ag.com/files/FMC Annual_Report_2013_en.pdf.

Gilg, J., Rao, A. \& Fogarty, D. (2013). UK Renal Registry $16^{\text {th }}$ Annual Report: Chapter 1 UK Renal Replacement Therapy Incidence in 2012: Centre-specific Analyses. Retrieved from: http:/www.renalreg.com/ReportArea/Report\%202013/01-Chap-01.pdf.

Garc1'a-Llana, H., Remor, E., del Peso, G., Celadilla, O. \& Selgas, R. (2014). Motivational Interviewing Promotes Adherence and Improves Wellbeing in Pre-Dialysis patients with Advanced Chronic Kidney Disease. Journal of Clinical Psychology in Medical Settings, 21(1), pp 103-115.

Hanly, L. (2014). Can energy drinks damage your kidneys? Livestrong. com. Retrieved from: https://www. livestrong.com/article/308744-what-are-the-benefits-of-monster-energy-drinks/.

Hays, R.D., Kallich, J.D., Mapes, D.L., Coons, S.J., Amin, N., Carter, W. \& Kamberg, C. (1997). Kidney Disease Quality of Life Short Form (KDQOL-SFTM), Version 1.2: A Manual for Use and Scoring: Rand Santa Monica, CA.

Horigan, A., Rocchiccioli, J. \& Trimm, D. (2012). Dialysis and fatigue: implications for nurses-a case study analysis. Medsurg nursing: official journal of the Academy of Medical-Surgical Nurses, 21(3), pp 158-175

Ibrahim, G. (2015). The Common Presenting Features and Stage of Chronic Kidney Disease in Newly Diagnosed patients in Khartoum Teaching Hospital. University of Khartoum, Sudan.

Karolich, R.L. \& Ford, J.P. (2010). Meaning, comprehension, and manageability of end-stage renal disease in older adults living with long-term hemodialysis. Social Work in Healthcare, 49(1), pp 19-37.

Kutner, N.G. (2012). Kidney disorders: end stage renal disease/dialysis. In: JH Stone, M Blouin, editors. International Encyclopedia of Rehabilitation. Retrieved from: http://cirrie.buffalo.edu/encyclopedia/ en/article/284

Mehrabi, Y., Ghazavi, Z. \& Shahgholian, N. (2017). Effect of Fordyce's happiness program on stress, anxiety and depression among the patients undergoing hemodialysis. Iranian Journal of Nursing and Midwifery Research, 22(3), pp 190-194. 
Navaseelan, U., Judenimal, K. \& Dioso, R. (2017). Diabetes mellitus complications among Srilankan adults admitted to two government hospitals: a cross-sectional study. The Malaysian Journal of Nursing, 9(2), pp 3-10.

Riyahi, Z., Esfarjani, F., Marandi, S.M. \& Kalani, N. (2012). The effect of intradialytic exercise training on fatigue and quality of life in hemodialysis patients. Journal of Research in Rehabilitation Sciences, 8(2), pp 219-227.

Shahgholian, N., Eshghinezhad, A. \& Mortazavi, M. (2014). The effect of tai chi exercise on quality of life in hemodialysis patients. Iranian Journal of Nursing and Midwifery Research, 19(2), pp 152-158.

Shaw, C., Pitcher, D., Pruthi, R. \& Fogarty, D. (2013). UK Renal Registry $16^{\text {th }}$ Annual Report: Chapter 2 UK RRT Prevalence in 2012: National and Centre-specific Analyses. Retrieved from: http://www.renalreg.com/ReportArea/Report\%202013/02-Chap-02.pdf.

Strand, H. \& Parker, D. (2012). Effects of multidisciplinary models of care for adult pre-dialysis patients with chronic kidney disease: A Systematic Review. International Journal of Evidence-Based Healthcare, 10(1), pp 53-59.

Suliman, M., Barany, P., Filho, J., Lindholm, B. \& Bergstrom, J. (2002). Accumulation of taurine in patients with renal failure. Nephrology Dialysis Transplantation-Oxford Journals, 17(3), pp 528-529.

Tao, X., Chow, S.K. \& Wong, F.K. (2015). A Nurse-Led Case Management Program on Home Exercise Training for Hemodialysis Patients: A Randomized Controlled Trial. International Journal of Nursing Studies, 52(6), pp 1029-1041.

World health organization (2004). Appropriate body-mass index for Asian populations and its implications for policy and intervention strategies. Lancet, 363(9403), pp 157-163.

Yanjmaal, E., Byambasukh, O., Kannenberg, S., Khasag, A., Dambadarjaa, D. \& Dalkh, T. (2018). Clinical and laboratory risk factors of newly diagnosed with type 2 diabetes adults. The Malaysian Journal of Nursing, 9(4), pp 93-98. 